\title{
Interpretation of Single Band Patterns in CSF Protein Electrophoresis
}

\author{
B.H. Bass, H. Armstrong, B. Weinshenker, G.C. Ebers, \\ J.H. Noseworthy and G.P.A. Rice
}

\begin{abstract}
We have examined the diagnostic significance of finding one band in the immunoglobulin (IgG) region in spinal fluid protein electrophoresis. From January 1983 to January 1986, 855 consecutive CSF electrophoreses were performed on as many patients. A blinded observer identified a single band in the IgG region in 53 cases (6.2\%). In only 14 patients (26\%), were the clinical features ultimately felt to be due to clinically definite or possible multiple sclerosis (MS). The majority of patients with a single band had another neurological diagnosis (55\%) or were neurologically normal (6\%). Many of the neurological disorders in which a single band was found were not disorders in which an increased intrathecal synthesis of immunoglobulin or electrophoretic restriction would have been expected. A variety of conditions can produce a single band pattern. The significance of these patterns and the means by which they might be identified are described.
\end{abstract}

RÉSUMÉ: Interprétation des profils électrophorétiques à bande unique du LCR. Nous avons examiné la signification diagnostique de l'observation d'une bande dans la région des immunoglobulines (IgG) à l'électrophorèse des protéines du liquide céphalo-rachidien. De janvier 1983 à janvier 1986, 855 électrophorèses de protéines du LCR ont été effectuées chez autant de patients. Un observateur ignorant les données cliniques a identifié une bande unique dans la région des IgG chez 53 cas (6.2\%). Les manifestations cliniques ont été attribuées en fin de compte à une sclérose en plaques cliniquement définie ou possible chez seulement 14 patients (26\%). La majorité des patients chez qui on a détecté une bande unique avaient un autre diagnostic neurologique (55\%) ou étaient neurologiquement normaux (6\%). Plusieurs des affections neurologiques dans lesquelles on a trouvé une bande unique n'étaient pas des affections dans lesquelles on s'attendrait à trouver une augmentation de la synthèse intrathécale d'immunoglobuline ou une restriction électrophorétique. Des affections variées peuvent produire un profil à bande unique. Nous décrivons la signification de ces profils et les moyens de les identifier.

Can. J. Neurol. Sci. 1988; 15:20-22

The usefulness of electrophoresis of cerebrospinal fluid (CSF) in patients with multiple sclerosis (MS) have been confirmed in several laboratories. ${ }^{1-4}$ In 1984 we reviewed our experience with the serial electrophoresis of more than 2,150 samples. In patients with clinically definite MS, $92 \%$ had oligoclonal banding. In patients with a diagnosis of possible MS, bands were identified in $38 \%$ and in patients with other neurological diseases (OND), bands were found in 9\%.' Many of the patients with OND who were shown to have oligoclonal bands were identified ultimately to have disorders associated with ongoing immune responses or inflammatory diseases in the central nervous system.

As our experience with agarose electrophoresis has increased, we have found several instances in which only a single band was identified in the gammaglobulin region. We have attempted to determine the diagnostic significance of this finding.

\section{Patient Material}

CSF samples were submitted to the University Hospital biochemistry laboratory for electrophoresis. These were provided largely by members of the Department of Clinical Neurological Sciences at the University of Western Ontario. Additional samples were submitted from other regional hospitals. We considered both the tentative diagnosis at the time of referral, and ultimate diagnosis, which was determined by chart review and patient follow-up. The diagnosis was unavailable in 3 patients whose CSF was sent from another hospital. Follow-up was incomplete in another 4 individuals. Patients were divided into groups of clinically definite MS (CDMS), possible MS (including Rose's possible and probable MS), ${ }^{5}$ or other neurological diseases (OND). 


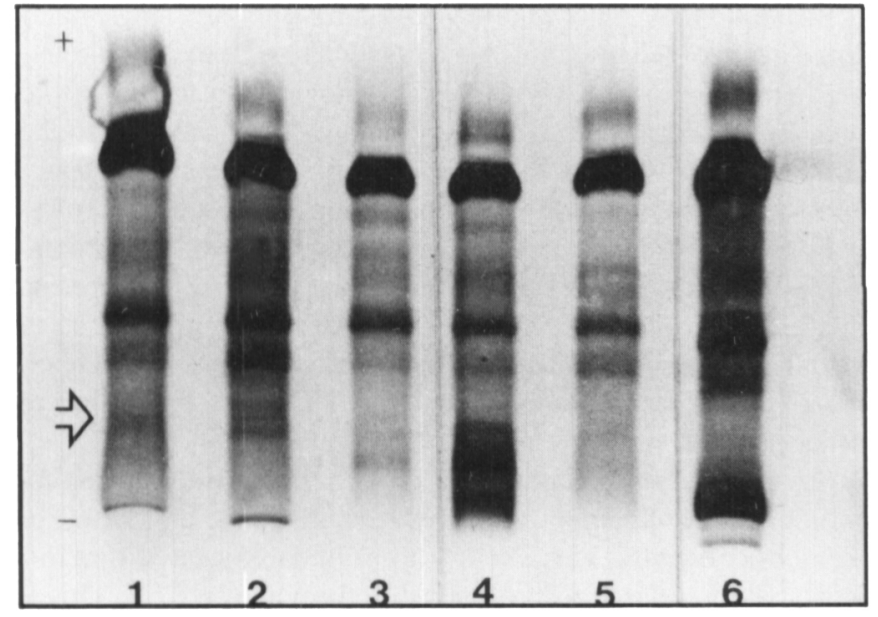

Figure I - Lane I demonstrates the appearance of the gamma trace protein, a sharp band at the leading cathodal edge. Lane 2 also shows gamma trace protein, and a single band zoned more anodally. Lane 3 reveals a single band pattern, and lane 4, a typical oligoclonal banding pattern. A sample without bands is shown in lane 5, and the appearance of $a$ monoclonal protein is demonstrated in lane 6. The sample application point is marked by an arrow.

\section{METHODS}

CSF obtained by lumbar puncture was concentrated approximately 100 fold in Minicon B15 filters (Amicon Corporation, Lexington, Massachusetts). Most of the samples were analyzed by a commercially available agarose gel electrophoresis system (Panagel - Millipore Corporation, Bedford, Massachusetts). The method for performing the electrophoresis has been described previously. ${ }^{3}$ Some samples were submitted to electrofocusing in agarose using a method previously described from this laboratory. ${ }^{6}$

The presence of IgG and the location of gamma and beta trace proteins were determined by standard immunofixation methods. ${ }^{7}$ Rabbit antigamma and beta trace (a generous gift of Dr. Anders Grubb, Sweden) which had bound to these proteins was probed with peroxidase conjugated anti-immunoglobulin. The bound conjugate was visualized with the chromogenic substrate 3 amino-9-ethylcarbazole. ${ }^{8}$ Immunoglobulin bands were probed with a goat antibody to human Fc fragment.

\section{RESULTS}

\section{Distribution of Diagnoses}

Between January 1983 and January 1986, electrophoreses were performed on 855 individuals. A blinded observer identified a single band in the gammaglobulin region in 53 cases (6.2\%). The referral diagnoses at the time of the electrophoresis are shown in Table 1 . The majority ( 29 of 53) were suspected of having MS.

When the ultimate diagnosis was determined, most of the patients with a single band (32/53) were shown to have another neurological disease or have no neurological problem (Table 2). No diagnosis was available in 3 of 53 , and follow-up was incom- plete in $4 / 53$. The list of neurological conditions in which a single band was demonstrated is shown in the footnote. ${ }^{*} \mathrm{~A}$ diagnosis of clinically definite MS was ultimately reached in 4 of the 53 patients and the diagnosis of MS was still considered probable in $10 / 53$.

\section{Types of Single Band Patterns}

Several proteins can produce a single band pattern. One of the most commonly seen protein bands that could be mistaken for a single immunoglobulin band is gamma trace protein. Gamma trace is a protein with a molecular weight of 12,000 found in a number of body fluids. Its biological significance is unknown. It is most commonly seen at the leading cathodal edge. Samples in which this band alone was demonstrated were not considered to show a "single band" unless there was a more anodal band. The single band at the cathodal edge was proven to be a gamma trace protein by immunofixation techniques using an antiserum specific to that particular protein.

In some specimens, a more anodally situated band, which was seen either alone or in conjunction with the cathodally situated gamma trace protein, was shown by immunofixation to be beta trace protein, the breakdown product of gamma trace protein. This band or "zone" when present was seen in many if not all CSF specimens run on the same plate.

There was no essential difference in the ultimate diagnosis found in patients whose single pattern was also associated with a gamma trace protein at the cathodal front. (Table 3)

\begin{tabular}{lcc}
\hline Table 1: Referral Diagnosis & & \\
\hline \hline & No. of Patients & $\%$ \\
\hline Possible MS & 28 & $(52.8)$ \\
Definite MS & 1 & $(1.9)$ \\
OND & 21 & $(39.6)$ \\
None & 3 & $(5.7)$ \\
\cline { 2 - 3 } & 53 & 100 \\
\hline
\end{tabular}

Table 2: Follow-up Diagnosis

\begin{tabular}{lcc}
\hline \hline & No. of Patients & $\%$ \\
\hline OND or Normal & 32 & $(60.4)$ \\
Possible MS & 10 & $(18.8)$ \\
Definite MS & 4 & $(7.5)$ \\
No Diagnosis Available & 3 & $(5.8)$ \\
No Follow-up & 4 & $(7.5)$ \\
\cline { 2 - 2 } & 53 & 100 \\
\hline
\end{tabular}

Table 3: Follow-up Diagnosis

\begin{tabular}{|c|c|c|c|c|}
\hline & $\mathbf{n}$ & $\begin{array}{c}\text { Gamma } \\
\text { Trace + } \\
\text { Single } \\
\text { Band } \\
(\%)\end{array}$ & $\mathbf{n}$ & $\begin{array}{l}\text { Single } \\
\text { Band } \\
\text { (\%) }\end{array}$ \\
\hline $\begin{array}{l}\text { Definite MS } \\
\text { Possible MS } \\
\text { OND } \\
\text { No Diagnosis }\end{array}$ & $\begin{array}{r}1 \\
9 \\
17 \\
3\end{array}$ & $\begin{array}{r}3 \\
30 \\
57 \\
10\end{array}$ & $\begin{array}{r}3 \\
6 \\
14 \\
-\end{array}$ & $\begin{array}{l}13 \\
26 \\
61 \\
- \\
\end{array}$ \\
\hline No Diagnosis & 30 & 100 & 23 & 100 \\
\hline
\end{tabular}

\footnotetext{
* Confusional state, degenerative diseases: Parkinson's disease, ${ }^{2}$ amyotrophic lateral sclerosis, cerebellar degeneration, ${ }^{2}$ Adie's syndrome, functional weakness, ${ }^{2}$ ischemic optic neuropathy, ${ }^{2}$ meningitis, monoclonal gammopathy, neuropathies: diabetic, Guillain-Barre, paraneoplastic, no neurological disease, ${ }^{3}$ normal pressure hydrocephalus, radicular syndromes, ${ }^{3}$ seizures, ${ }^{2}$ strokes, ${ }^{2}$ subarachnoid hemorrhage, transient ischemic attacks, ${ }^{2}$ tumours: pituitary adenoma, metastatic adenocarcinoma.
} 
Table 4: Follow-up Diagnosis

\begin{tabular}{llllc}
\hline \hline & \multicolumn{3}{c}{ Oligoclonal Bands After Focusing } \\
& + & - & ? & 1 Band \\
\hline Definite MS & 2 & 1 & 0 & 0 \\
Possible MS & 4 & 5 & 5 & 0 \\
Not MS & 2 & 5 & 2 & 2 \\
\hline
\end{tabular}

Isoelectric focusing is much more sensitive than agarose electrophoresis in demonstrating bands, but is also less specific. With this technique proteins are separated on the basis of isoelectric point in a relatively continuous $\mathrm{pH}$ gradient. We focused twenty-eight samples in which a single band appeared in agarose electrophoresis. Multiple bands were demonstrated in 8, the single band persisted in 2 cases, the bands were no longer evident in 11, and in 7 no conclusion could be drawn. The demonstration of oligoclonal bands by isoelectric focusing did not improve the diagnostic confidence at the time of follow-up. The diagnostic stratification was similar, regardless of whether isoelectric focusing resolved single bands into multiple bands, no bands, one band or an uncertain pattern (Table 4).

One individual was shown to have a monoclonal gammopathy. In this patient the band which was broad and distinct in CSF, was present in serum as well. When this was focused the bands resolved into 6 very closely spaced bands. Immunofixation with an anti-IgG overlay indicated that this was an IgG gammopathy of monoclonal origin.

\section{DisCuSSION}

The proportion of patients with one band who were shown to have MS or possible MS, was only $26 \%$. A wide variety of neurological conditions is more commonly associated with the presence of this abnormality. It is interesting that patients with "other neurological diseases" who have a single band in their CSF differ from those who have multiple bands in that most of those patients with a single band do not have neurological illnesses known to be associated with an ongoing immune response in the central nervous system. ${ }^{1}$

We have identified some of the artifacts which can obscure the interpretation of banding patterns. The presence of gamma trace protein presents little problem when it appears by itself. It commonly appears as a single band, often at the leading edge of the cathodally migrating proteins. We did not consider this appearance indicative of a "single band". However, if this pattern occurred in conjunction with any more anodal band, we did consider this to represent a single band pattern, distinct from the oligoclonal banding pattern.

Not only was gamma trace protein demonstrable but also its breakdown product, beta trace was visualized by immunofixation. It is well established that normal CSF will produce banding patterns on agar gel electrophoresis consisting of beta trace protein, which could produce a band in the anodal part of the gammaglobulin region, and gamma trace which produces a single band cathodally. The IgG migrates as a diffuse zone between these. ${ }^{9}$ In contrast, in approximately $90 \%$ of MS patients, multiple bands can be seen in the gammaglobulin region using agarose gel electrophoresis. ${ }^{1}$
We found that in 8 of 28 cases the agarose defined single band could be resolved into multiple bands with an isoelectric focusing technique indicative of the immunoglobulin nature of the band. This did not increase the likelihood that the underlying condition was MS. Further follow-up for these patients might allow us to understand this phenomenon more completely.

For diagnostic purposes, the visual inspection of the gammaglobulin bands is more important than knowing the precise quantity of proteins. Link has emphasized the importance of visual inspection and the need for sufficient experience in reading electrophoretic plates so as to avoid misinterpretation of other protein bands in the gamma globulin region. ${ }^{9}$

Several investigators have noted a change in the electrophoretic mobility of gamma trace towards the anode on storage or aging of concentrated CSF. ${ }^{10,11}$ It has been suggested that this shift may be related to proteolytic activity in the CSF. This is another variable which may cause misinterpretation of agarose electrophoretic banding patterns and in particular, a single band pattern.

Agarose gel electrophoresis remains a very convenient diagnostic tool in the assessment of patients with symptoms suggestive of MS. In only a small percentage of patients is a single band found and in most of these, the diagnosis is shown not to be MS.

\section{ACKNOWLEDGEMENTS}

This work was supported by the Multiple Sclerosis Society. GCE and GPAR are supported by the Ministry of Health of Ontario. JN and BW are supported by the Multiple Sclerosis Society of Canada. Donna Greer provided expert secretarial assistance.

\section{REFERENCES}

1. Ebers GC. Oligoclonal banding in multiple sclerosis. Ann NY Acad Sci 1984; 436: 206-212.

2. Lowenthal A, Van Sande M and Karcher D. The differential diagnosis of neurological diseases by fractionating electrophoretically the CSF-globulins. J Neurochem 1960; 6: 51-60.

3. Johnson KP, Arrigo SC, Nelson BJ, et al. Agarose electrophoresis of cerebrospinal fluid in multiple sclerosis. Neurology 1977; 27: 273-277.

4. Hershey LA and Trotter JL. The use and abuse of the cerebrospinal fluid IgG profile in the adult: A practical evaluation. Ann Neurol 1980; 8: 426-434.

5. Rose AS, Ellison G, Myers L, et al. Criteria for the clinical diagnosis of multiple sclerosis. Neurology 1976; 26: 20-22.

6. Voulters L, Ebers GC. Neurology 1984; 34 (Suppl): 227 (abstract).

7. Mattson DH, Roos RP, Arnason BGW. Immunoperoxidase staining in cerebrospinal fluid $\mathrm{IgG}$ in isoelectric focusing gels. A sensitive new technique. J Neurosci Methods 1980; 3: 67-75.

8. Graham RC, Lundholm U, Karnovsky MJ. Cytochemical demonstration of peroxidase activity with 3 amino-9-ethylcarbazole. J Histochem Cytochem 1965; 13: 150-152.

9. Link $H$. Immunoglobulin $G$ and low molecular weight proteins in human cerebrospinal fluid. Acta Neurol Scand 1967; 43 (Suppl. 28): 1-136.

10. Hochwald GM and Thorbecke GJ. Trace proteins in cerebrospinal fluid and other biological fluids. II Effect of storage and enzymes on the electrophoretic mobility of gamma trace and beta trace proteins in cerebrospinal fluid. Clin Chim Acta 1963;8: 678-684.

11. Laterre EC and Heremans JF. A note on proteins apparently "specific" for cerebrospinal fluid. Clin Chim Acta 1963; 8: 220. 